\title{
Adaptation of Biotrophic Leaf Pathogens to Fertilization-Mediated Changes in Plant Traits: A Comparison of the Optimization Principle to Invasion Fitness
}

\author{
Pierre-Antoine Précigout, ${ }^{1,2, \dagger}$ Corinne Robert, ${ }^{1}$ and David Claessen ${ }^{2}$ \\ ${ }^{1}$ UMR EcoSys, INRAe-AgroParisTech, 78850 Thiverval-Grignon, France \\ ${ }^{2}$ Institut de Biologie de l'Ecole Normale Supérieure, CNRS-ENS-INSERM UMR8197, Ecole Normale Supérieure, 75005 Paris, France \\ Accepted for publication 8 January 2020.
}

ABSTRACT

\begin{abstract}
One of the conclusions of evolutionary ecology applied to agroecosystem management is that sustainable disease management strategies must be adaptive to overcome the immense adaptive potential of crop pathogens. In this context, knowledge of how pathogens adapt to changes in cultural practices is necessary. In this article we address the issue of the evolutionary response of biotrophic crop pathogens to changes in fertilization practices. For this purpose, we compare predictions of latent period evolution based on three empirical fitness measures (seasonal spore production, within-season exponential growth rate, and area under disease progress curves [AUDPCs]) with predictions based on the concept of invasion fitness from adaptive dynamics. We use pairwise invisibility
\end{abstract}

plots to identify the evolutionarily stable strategies (ESSs) of the pathogen latent period. We find that the ESS latent period is in between the latent periods that maximize the seasonal spore production and the within-season exponential growth rate of the pathogen. The latent periods that maximize the AUDPC are similar to those of the ESS latent periods. The AUDPC may therefore be a critical variable to determine the issue of between-strain competition and shape pathogen evolution.

Keywords: adaptive dynamics, fertilization, interaction between strains, invasion fitness, optimization principle, pathogen fitness, pathogen adaptation, plant traits
The development of sustainable agriculture requires us take into account pathogen adaptation to agricultural practices (Bousset and Chèvre 2013; Denison 2012; Gilligan 2007; McDonald and Linde 2002; Zhan et al. 2014, 2015). Processes that have received much attention to date relate to pathogen evolution in response to the use of pesticides (Brent and Hollomon 2007; Deising et al. 2008; Fisher et al. 2018; Gullino et al. 2000; Hahn 2014; Hayes et al. 2016; Hewitt 1998; Ma and Michailides 2005; REX Consortium 2015; Sierotzki and Scalliet 2013; Urech et al. 1997; Walker et al. 2017) as well as resistant cultivars (Biffen 1905; Fabre et al. 2015; Kilpatrick 1975; McDonald and Linde 2002; McIntosh and Brown 1997; Rimbaud et al. 2018). These studies show that such pathogen control methods are usually not sustainable because of pathogen adaptation. Here, we refer to these control methods that aim to eradicate pathogens as hard regulation practices. What has received much less attention is the evolution of pathogens in response to cultural practices, which have a less direct impact on pathogens and regulate epidemics to a lesser extent. Such practices, which we refer to as soft regulation practices, include crop and cultivar mixtures (Mikaberidze et al. 2015; Mundt 2002; Tooker and Frank 2012), sowing date or density (Baccar et al. 2011), tillage (Bockus and Shroyer 1998; Rothrock 1992), and crop fertilization (reviewed by Dordas 2008 and Walters and Bingham 2007). These practices have partial and quantitative effects on epidemics. Knowledge of

†Corresponding author: P.-A. Précigout; pierre-antoine.precigout@cri-paris.org

Funding: P.-A. Précigout received funding from the Institut National de la Recherche Agronomique in the form of a Contrat Jeunes Scientifiques grant.

*The $e$-Xtra logo stands for "electronic extra" and indicates that one supplementary figure and one supplementary appendix is published online.

The author(s) declare no conflict of interest.

This article is in the public domain and not copyrightable. It may be freely reprinted with customary crediting of the source. The American Phytopathological Society, 2020. the evolutionary responses of pathogens to such soft regulation practices and the trade-offs constraining their evolution is essential in order to design innovative scenarios combining several diseaseregulating methods (not only in terms of pesticides and cultivar resistance). Such practices are of particular interest in the context of pathogen regulation through agroecological approaches, especially when the objective of pesticide nonuse in agroecosystems is considered.

Soft regulation practices are thought to be more sustainable than hard regulation practices (French et al. 2016; Mundt 2014; Pariaud et al. 2009). A major difference is that with soft regulation, epidemics occur in the field, as opposed to in theory with hard regulation. Evolutionary processes are likely to be different in the two cases, with the selection pressure probably being stronger in the case of hard regulation (Hartl and Clark 1997; Oz et al. 2014; Stockwell et al. 2003; Ueda et al. 2017). Evolution in hard regulation practices often involves the expression of a limited number of genes, as exemplified by gene-for-gene or matchingallele interactions (Thrall et al. 2016). A single mutation in the pathogen may thus undo the plant's resistance. In the case of hard regulation, the evolving trait is usually of the Boolean type (true/ false) and often modeled via the population genetic approach (Thrall et al. 2016). In the case of soft regulation practices, the pathogen's adaptive response is more likely to be associated with quantitative traits (French et al. 2016; Pariaud et al. 2009). Here, we propose a modeling approach that focuses on a quantitative trait, namely the latent period. We model the response of a crop pathogen in terms of its latent period to changes in plant traits, which are determined by a soft regulation practice: the fertilization level (Précigout et al. 2017).

The evolutionary response of quantitative traits is modeled in evolutionary ecology through a variety of methods. Two classic methods are the optimization principle and evolutionary invasion analysis. In the first method, a given trait is optimized by maximizing a predefined fitness measure such as offspring production or the epidemiological quantity $R_{0}$. The optimization 
method has been applied widely in ecology to all kinds of quantitative traits in all kinds of biological systems (Roff 2002; Stearns 1992). It has also been applied in the context of crop pathogen evolution (Précigout et al. 2017; van den Berg et al. 2011). The Achilles heel of this method is the use of an arbitrary fitness measure. Indeed, the optimization of intuitively plausible fitness proxies does not necessarily result in correct predictions, unless it can be shown that the proxy corresponds to a robust measure of fitness (van den Berg et al. 2011). The invasion analysis method has also been applied in ecology in the adaptive dynamics literature, with applications in an agricultural context (Hamelin et al. 2011; van den Berg et al. 2010). In this method, a model of population dynamics is used to explicitly estimate the invasion fitness of mutants arriving in a population of resident types (Geritz et al. 1998; Metz et al. 1992). The advantage of this method is that, by definition, the concept of invasion fitness is a rigorous predictor of the direction of evolution and hence more reliable than any intuitive but arbitrary fitness measures used in the optimization method. But despite invasion fitness being theoretically more rigorous than any ad hoc fitness measure (Geritz et al. 1998; Metz et al. 1992), it is difficult to measure in an experimental context. For these reasons, we are interested in comparing the results obtained from both methods, with the idea that this cross-comparison can yield new biological and experimentally relevant insights.

In a previous article (Précigout et al. 2017), we developed a physiologically structured population model for the epidemiological dynamics of a biotrophic fungal crop pathogen while accounting explicitly for the growth of the crop canopy and the life history structure of the pathogen. In other words, the dynamics of lesions is modeled while their age-dependent life history is tracked, including the latent period and a sporulation phase. The growth and sporulation of pathogens depend on the available nutrient level and the lifespan of the leaf tissue. Through its explicit physiological structure, this model is well suited for studying the role of the latent period in epidemics. In that study, we used the optimization principle to identify optimal latent periods corresponding to potential evolutionary directions of the pathogen's latent period in response to crop fertilization (Précigout et al. 2017). We found a positive relation between the optimal latent period and the crop fertilization level when maximizing the seasonal spore production but a negative relation when maximizing the withinseason exponential growth rate. The lack of consensus about how to define and measure fitness for leaf crop fungal pathogens and filamentous fungi in general (Balodi et al. 2017; Gilchrist et al. 2006; Pringle and Taylor 2002; Zhan and McDonald 2013a) does not shed light on these contradictory results, which calls for further research.

In this work we pursued the question of the adaptation of pathogens to soft agricultural techniques by studying the potential evolutionary responses of the pathogen's latent period to crop fertilization. Our objective was to compare the evolutionary responses of the latent period to fertilization obtained via the optimization principle applied to three ad hoc fitness measures on one hand and invasion fitness from adaptive dynamics on the other. The three fitness measures on which we applied the optimization principle are the seasonal spore production, the within-season exponential growth rate of the pathogen, and the severity of the disease over the cropping season (area under disease progress curve [AUDPC]). We then used the invasion fitness method and realized a cross-comparison of the results obtained with the two methods. The comparison yielded insights regarding which of the fitness measures we used is better suited for the study of pathogenic filamentous fungi.

\section{MATERIALS AND METHODS}

Theoretical framework. We use the model of Précigout et al. (2017) that was designed as a consumer-resource model. This model explicitly takes into account the age-dependent life history of a pathogen feeding on the resources in the canopy's leaf tissue. The

TABLE 1. Biological model parameters and their default values representing the wheat leaf rust pathosystem

\begin{tabular}{|c|c|c|c|}
\hline Symbol & Value & Unit & Interpretation \\
\hline \multicolumn{4}{|c|}{ Seasonal dynamics } \\
\hline$T_{\text {end }}$ & 2,500 & Degree days $(\mathrm{dd})$ & End of season \\
\hline$T_{\text {grow }}$ & 1,500 & dd & End of canopy growth period \\
\hline$T_{\text {inoc }}$ & 1,000 & dd & Arrival date of primary inoculum (annual start date of epidemic) \\
\hline$\omega$ & 0.1 & - & Spore survival probability over an unfavorable season \\
\hline \multicolumn{4}{|c|}{ Plant dynamics } \\
\hline$K$ & 5 (varied) & $\mathrm{g}$ & Within-patch resource carrying capacity \\
\hline$\psi$ & 0.02 & $/ \mathrm{dd}$ & Export rate of resource from patch to common pool \\
\hline$R_{0}$ & 0.03 & $\mathrm{~g}$ & Initial resource level at patch creation \\
\hline$\phi_{0}$ & 0.3 & /dd & Intrinsic rate of photosynthesis (at age $a=0$ ) \\
\hline$\tau$ & 750 (varied) & dd & Maximum patch age for photosynthesis \\
\hline$R_{\min }$ & 0.02 & $\mathrm{~g}$ & Minimum resource level for patch survival \\
\hline$\rho$ & 1 (varied) & /dd & Maximum rate of patch creation \\
\hline$k$ & 1 & $\mathrm{~g} / \mathrm{dd}$ & Cost of patch creation \\
\hline$A_{H}$ & 100 & $\mathrm{~g}$ & Half-saturation pool resource level for patch creation \\
\hline \multicolumn{4}{|c|}{ Pathogen dynamics } \\
\hline$\lambda$ & 150 (varied) & dd & Latent period \\
\hline$M_{0}$ & 0.0001 & $\mathrm{~g}$ & Initial mycelium biomass at patch infection \\
\hline$I_{\max }$ & 0.06 & $\mathrm{~g} / \mathrm{dd}$ & Maximum resource uptake rate per unit of mycelium biomass \\
\hline$R_{H}$ & 0.25 & $\mathrm{~g}$ & Half-saturation constant for functional response \\
\hline$c_{m}$ & 0.2 & - & Conversion coefficient resource for mycelium \\
\hline$c_{s}$ & 0.2 & - & Conversion coefficient resource for spores \\
\hline$\gamma_{m}$ & 0.001 & $/ \mathrm{dd}$ & Mycelium decay rate \\
\hline$\gamma_{s}$ & 0.001 & $/ \mathrm{dd}$ & Spore decay rate \\
\hline$c_{\mathrm{LTR}}$ & 50 & $/ g$ & Constant for computation of LTR \\
\hline \multicolumn{4}{|l|}{ Dispersal } \\
\hline$\beta$ & 0.4 & - & Dispersal efficiency \\
\hline$\Delta$ & 250 & dd & Maximum dispersal distance (in terms of patch age) \\
\hline$a_{\text {inoc, } \min }$ & 20 & dd & Minimum patch age to receive primary inoculum \\
\hline$a_{\text {inoc, } \max }$ & 250 & dd & Maximum patch age to receive primary inoculum \\
\hline$\theta_{\max }$ & 0.02 & - & Maximum fraction of patches per cohort that can be inoculated \\
\hline$P_{H}$ & 10 & $\mathrm{~g}$ & Half-saturation spore biomass for spores (limited inoculation) \\
\hline
\end{tabular}


model was parameterized to resemble the wheat leaf rust pathosystem (Table 1) (Précigout et al. 2017). In the following section, we give an overview of the model and present the modeling hypothesis we deemed necessary to understand the work presented in this article.

Our model accounts for two levels of organization: the foliar patch scale and the canopy scale. The crop canopy is modeled as the age distribution of elementary leaf surfaces' named patches. A patch is roughly the size of a fungal lesion, being a few square centimeters of the leaf surface. Each patch represents a quantity of resource $R$. This resource is renewed by photosynthesis as long as the patch is alive. The patch resource has two possible futures: (i) being exported to the rest of the plant and contributing to the growth of the plant by creating new patches or (ii) being used by the fungus for the production of its biomass of mycelium or spores. Our model simulates (i) within-patch dynamics at a local scale on plant leaves and (ii) the dynamics of the number of patches that make up the crop canopy. At the patch scale, we model physiological processes such as within-plant nutrient dynamics, leaf senescence, nutrient consumption by the pathogen, mycelium growth, and spore production. At the canopy scale, we model ecophysiological processes such as canopy growth (in terms of the number of patches and their age structure) and the dynamics of the epidemics, including the infection of healthy patches resulting from spore dispersal within the canopy.

We incorporate spatial structure into the model by assuming that the distance between patches correlates with the difference in patch age. The patch's vertical position in the canopy is considered proportional to the time in the season when it was formed. The youngest patches are hence found at the top of the canopy, and the oldest crop tissue is found at its base. Canopy growth is then modeled as an increase in the number of patches (at the top), while existing patches simply grow older.

The infection of healthy patches creates lesions that are accounted for in the model as the infected part of the canopy. The lesion dynamics are modeled while accounting for their agedependent life history, including a latent period (devoted to mycelium growth) and a sporulation phase (devoted to asexual reproduction). The growth and sporulation of the pathogens depend on the locally available nutrient level. Following Gilchrist et al. (2006), we assume that pathogens display the so-called bangbang resource allocation strategy: All resources are allocated to mycelium (somatic) growth during the latent period, and all resources are allocated to reproduction during the subsequent sporulation period.

The model represents the within- and between-season dynamics of a growing cereal canopy (wheat). The canopy is reseeded each year and provides the substrate for the dynamics of a rustlike polycyclic disease. Time is expressed in degree-days (dd). We denote time by $t$, and $T$ corresponds to the date within a given year (time is in dd since the start of the current year). One year is 2,500 dd long. At the start of the year $(T=0)$, a single patch of age $a=0$ is created corresponding to the emerging wheat seedlings. The canopy then grows in size (number of patches) from $T=0 \mathrm{dd}$ to $T_{\text {growth }}=$ $1,500 \mathrm{dd}$, after which time its size remains stationary (from $T_{\text {growth }}$ dd to $T_{\text {end }}=2,500 \mathrm{dd}$ ). Epidemics are initiated at the date $T_{\text {inoc }}=$ $1,000 \mathrm{dd}$. This represents the onset of leaf rust epidemics, which usually begin in April or May in Western Europe, that is, 1,000 to $1,300 \mathrm{dd}$ after crop sowing depending on environmental conditions (Duvivier et al. 2016; El Jarroudi et al. 2014). Finally, the last phase represents the harvest of the crop and the intercropping. This phase is modeled as an instantaneous projection from $T_{\text {end }}$ to the start of the next year. Every year, an epidemic is inoculated from a spore pool that results from the preceding season's epidemics. This quantitative dependence between subsequent years enables us to compute both the long-term (steady state) dynamics and the pathogen's invasion fitness.

Equations of the model are presented in Supplementary Appendix S1. Parameters of the model are provided in Table 1.
Further information about the modeling choices and parameterizing is given in Précigout et al. (2017).

Simulating effects of crop fertilization. In our study, changes in fertilization levels are simulated through changes in three plant traits: (i) within-leaf metabolite concentration (MC effect), (ii) leaf lifespan (LL effect), and (iii) canopy size (leaf area index [LAI] effect) (Précigout et al. 2017). The first two correspond to changes in resource availability at the patch scale, and the third corresponds to changes in canopy density (multipatch or canopy scale). We simulate pathogen responses to the three fertilizationtriggered plant traits independently.

To simulate the effect of fertilization on the MC effect, we change within-patch resource levels by modifying the patch resource carrying capacity $K$ (Fig. 1 and Equations 1 and 3 in Supplementary Appendix S1), for example, the maximum amount of resource $R$ in the individual patches. This scenario mimics the increased concentration of primary metabolites in leaves in highly fertilized crops.

To simulate the LL effect, we change patch lifespan by varying the parameter $\tau$ (Fig. 1 and Equation 2 in Supplementary Appendix $\mathrm{S} 1)$. This scenario mimics the increased lifespan in leaves in highly fertilized crops.

To simulate the effect of fertilization on the LAI effect, we change the maximum patch creation rate $\rho$ (Fig. 1 and Equation 7 and 11 in Supplementary Appendix S1). This scenario mimics the increase in canopy size in highly fertilized crops.

Empirical fitness measures. Based on the knowledge of fungal biology, we use three empirical fitness measures.

The first is the pool of spores remaining at the end of the cropping season, denoted by $P\left(T_{\text {end }}\right)$. Notwithstanding the rate of spore decay, it represents the spore production over the entire season. It is calculated as the number of viable spores at the end of the cropping season (solution to Equation 12 in Supplementary Appendix S1).

The second measure is the within-season exponential growth rate of the pathogen, denoted by $r$. This measures how fast the pathogen colonizes the canopy at the beginning of the epidemics. It is computed as:

$$
r=\frac{\log (\mathrm{LTR})}{\lambda}=\frac{\log \left(c_{\mathrm{LTR}} \cdot S\left(a_{T_{\mathrm{end}}}\right)\right)}{\lambda}
$$

The quantity LTR corresponds to the patch-level lifetime reproductive success, that is, the contribution of each patch in the model to the number of spores remaining at the end of the season $S\left(a_{\text {Tend }}\right)$. This measure is interesting, because the pathogen triggers a race between canopy growth and canopy colonization (Robert et al. 2018). If the pathogen is not fast enough to keep up with canopy growth, the plant may escape the disease. This fitness measure is an attempt to account for the effect of the latent period on the generation time by converting the lesion-level spore production into an estimate of the exponential population growth rate.

The third empirical fitness measure is the AUDPC (Madden et al. 2007). The AUDPC corresponds to an integrated measure of epidemic intensity over time (Agrios 2005). Here, AUDPC is computed as the integral of the number of sporulating patches over the season (the infectious part of infected patches in Equation 8 in Supplementary Appendix S1). This fitness measure is an attempt to account for the effect of the latent period on both the speed and intensity of the canopy colonization.

Invasion fitness. The fourth fitness measure used in this study is invasion fitness, as defined in adaptive dynamics (Metz et al. 1992). This fitness measure is defined as the long-term (multiannual) exponential growth rate of a second pathogen strain, referred to as a mutant, which attempts to invade the system composed of the crop and the first strain, now referred to as the resident (Metz et al. 1992). This requires the assumption that the mutant strain remains at a negligible population density during the invasion process, such that it does not exert any density dependence 
on the first strain (Geritz et al. 1998). In our model, we obtain this condition rigorously by (artificially) assuming that the second strain does not influence the number of healthy patches available for infection. In other words, the dynamics of the mutant strain is enslaved by the dynamics of the resident strain. The interaction between the two strains occurs exclusively through the dynamics of available healthy patches, because we exclude multiple infections of single patches (which is a reasonable assumption given the patch size). The healthy patch distribution hence represents the relevant environment (in the sense of Diekmann 2004; Metz et al. 2008) for which competition between strains would take place.

Mathematically, the environment of pathogen strains is defined as the distribution of healthy patches $(h[t, a]$ in Equations 6 and 7 in Supplementary Appendix S1). The assumption that the mutant does not exert any density dependence on the environment therefore requires for the mutant population not to influence the dynamics of the healthy patches $(h[t, a])$. Otherwise, the dynamics of the mutant are modeled identically to the resident's dynamics. We duplicate the equations describing the dynamics of the distribution of the patches infected by the resident $(n[t, a, b]$ Equations 8 to 10 in Supplementary Appendix S1) in order to describe the dynamics of the mutant's distribution $(m[t, a, b]$ in Equation 8 to 10 in Supplementary Appendix S1). The assumption that the mutant does not exert any density dependence on the environment requires that (i) any new infections created by mutant patches are not removed from the healthy canopy (Equation 6 in Supplementary Appendix S1) and that (ii) the resources exported from patches infected by mutants do not influence the dynamics of the common resource pool $A(t)$ (Equation 11 in Supplementary Appendix S1). In the absence of any density dependence, the dynamics of the mutant population distribution $(m[t, a, b])$ are necessarily exponential, once the effect of the initial conditions has dissipated. Any quantitative measure of the mutant population distribution $m(t, a, b)$ (e.g., the total population density or the pathogen population dynamics) can then be used to estimate its exponential rate of growth or decline (Claessen and Dieckmann 2002).

The invasion fitness of a mutant with latent period $\lambda_{2}$ invading a resident with latent period $\lambda_{1}$ is computed as the log of the ratio of the mutant's spore pool $P_{2}\left(T_{\text {inoc }}\right) y$ at the beginning of the epidemic lasting two successive years (denoted by $y$ and $y+1$ ), once the system has settled into its steady state (and the mutant has reached exponential growth):

$$
f\left(\lambda_{2}, \lambda_{1}\right)=\log \frac{P_{2}\left(T_{\text {inoc }}\right)_{y+1}}{P_{2}\left(T_{\text {inoc }}\right)_{y}}
$$

where $P_{2}\left(T_{\text {inoc }}\right)$ is the quantity of spores at the time of the inoculation of the epidemic.

In adaptive dynamics, it is usual to plot the invasion fitness function in a so-called pairwise invisibility plot (PIP), which depicts the sign of the function $f\left(\lambda_{2}, \lambda_{1}\right)$ over the two trait axes $\lambda_{1}$ and $\lambda_{2}$ (Geritz et al. 1998). Here, we present PIPs for several values of each
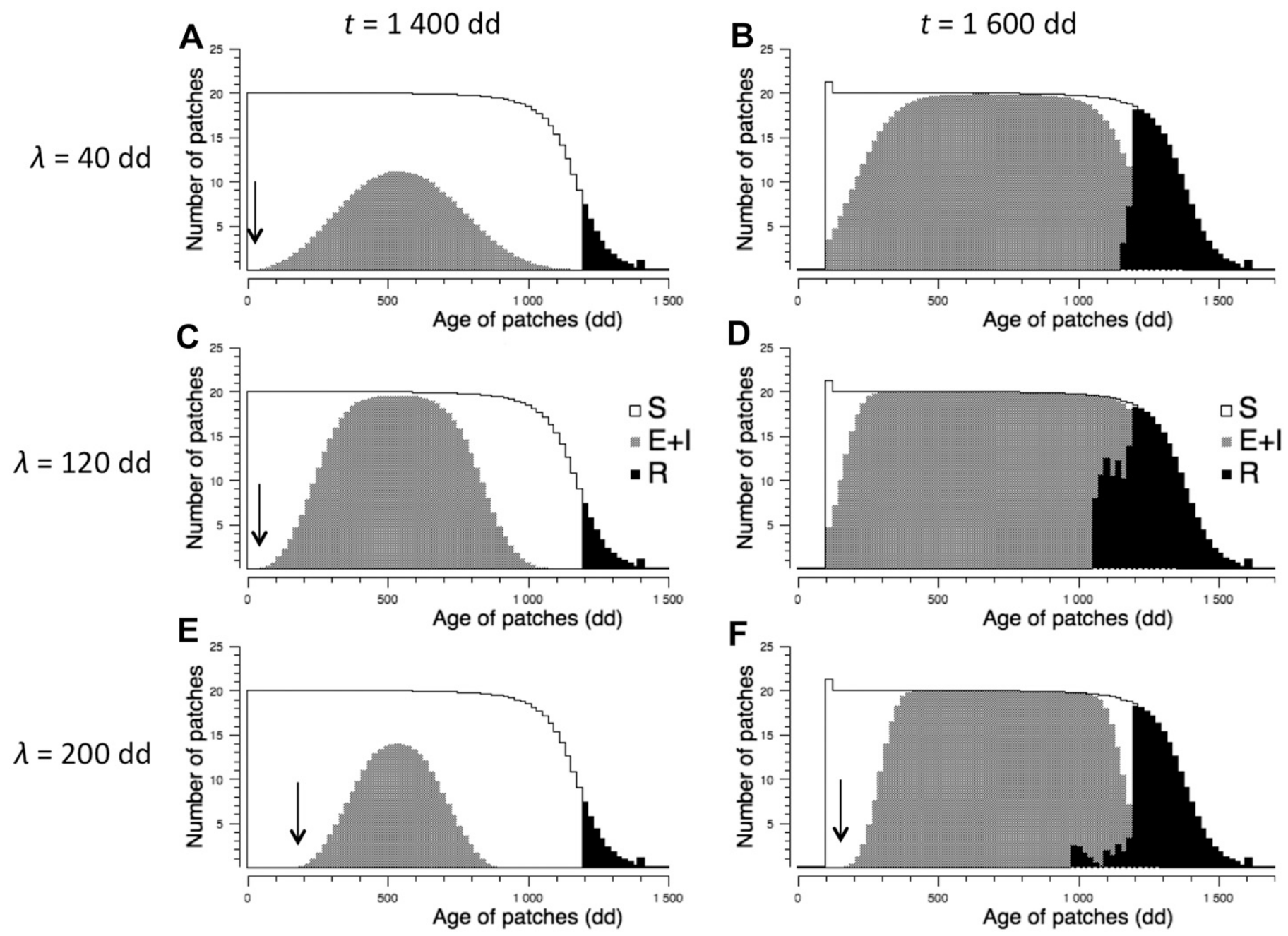

Fig. 1. Dynamics of the infection-specific age structure of the canopy for three latent periods $\lambda$ (rows), illustrated by snapshots at $\mathbf{A}, \mathbf{C}$, and $\mathbf{E}, t=1,400$ and $\mathbf{B}, \mathbf{D}$, and $\mathbf{F}, t=1,600 \mathrm{dd}$ (columns), at equilibrium. White, uninfected patches ("S"); gray, infected patches (latent "E" and infectious "I"); black, patches become dead ("R"). Fertilization parameters $K=5, \rho=1$, and $\tau=1,000$. Arrows indicate the youngest patches reached by the epidemics on the different snapshots. 
of the three studied fertilization parameters. A single PIP represents the outcome of the invasion process between a resident and a mutant pathogen strain that are completely identical but in their latent period. For each value of the latent period $\lambda_{1}$ of the resident strain, it describes which mutant strains with latent periods $\lambda_{2}$ are or are not capable of invading the environment defined by the resident $\left(f\left[\lambda_{2}, \lambda_{1}\right]>0\right.$ in Equation 2). Note that a PIP does not show the outcome of between-strain competition, because it is assumed that the invader has no impact on density dependence. After the invasion, a mutant strain with positive invasion fitness may either coexist with the resident or replace it. The invasion fitness is necessarily zero along the diagonal where the resident and mutant strains have identical latent periods. The boundaries between the areas with positive and negative invasion fitness are called zeroisoclines. The invasion fitness is also zero along these lines. The intersection of a zero-isocline with the diagonal defines an evolutionarily stable strategy (ESS): points at which the selection gradient vanishes. Such singular points may be either attractive or repulsive (Geritz et al. 1998).

Numerical analysis methods and simulations. The model was implemented via the Escalator Boxcar Train (EBT) method (de Roos 1997) and the EBTtool software package (de Roos 2014), both of which are designed to study the dynamics of physiologically structured population models. To determine the optimal latent periods for every resource scenario tested, we carried out sensitivity analyses for each corresponding fertilization-triggered plant traits $(K, \tau$, and $\rho$ representing MC, LL, and LAI plant traits, respectively, as defined above). For values of the fertilization parameter that are high enough to allow epidemic development, the relation between all three empirical fitness measures (spore production $P\left[T_{\text {end }}\right]$, pathogen exponential growth rate, $r$, and AUDPC, as defined above) and the latent period presented a maximum value. We termed the inverse images of these maximum values the optimal latent periods. These are the values of the latent period that maximize the empirical fitness measures and thus represent putative evolutionary responses in the case of changes in the fertilization level. In the presented figures, optimal latent periods can only be a multiple of 10 , because of the discretization of the partial differential equations into age classes of $10 \mathrm{dd}$ in the EBT implementation.

\section{RESULTS}

Figure 1 shows canopy and epidemic development for three latent period values $(\lambda=40,120$, and $200 \mathrm{dd})$ for a given fertilization level ( $K=5, \tau=1,000 \mathrm{dd}, \rho=1)$. Each subplot represents the dynamics of the infection-specific age structure of the canopy, with the old age classes of patches corresponding to the lower leaves near the ground and the young age classes of patches to the upper leaves at the top of the canopy. Figure 2 completes Figure 1 by showing the seasonal dynamics of the number of infected patches at equilibrium (Fig. 2A) and the corresponding cumulated spore production (Fig. 2B).

At $T=1,400 \mathrm{dd}$ (that is, $400 \mathrm{dd}$ after the onset of the epidemic), the pathogen with the short latent period $(\lambda=40 \mathrm{dd})$ has completed 10 infection cycles that resulted in infections of a wide range of age classes of patches (Fig. 1A). Indeed, the pathogen has already reached some of the youngest patches at the top of the canopy (arrows on Fig. 1A). Conversely, the pathogen with the long latent period $(\lambda=200 \mathrm{dd})$ has completed only two infection cycles. It did not infect as many age classes of patches as the pathogen with the short latent period (Fig. 1E): it is less effective at "climbing up" the canopy (arrows on Fig. 1E). The advantage of short latent periods in the race against canopy growth is visible again at $T=1,600 \mathrm{dd}$ : Whereas the pathogen with the short latent period has reached the top of the canopy, the one with the long latent period is still about 200 dd down from the top (cf. Fig. 1B and F). A long latent period thus results in a delay in reaching the youngest parts of the canopy (delay in "upward colonization" of the canopy). Nonetheless, epidemics with $\lambda=40$ and $\lambda=200$ lead to similar numbers of infected patches at any time during the cropping season (Fig. 2A). This is because the pathogen with the longest latent period has a higher spore production rate than the pathogen with the shortest latent period (the spore production is proportional to the mycelium biomass, which increases with the latent period; see Equation 13 in Supplementary Appendix S1). With a similar number of infected patches, the spore production associated with the short latent period of $40 \mathrm{dd}$ is much lower than the spore production associated with the long latent period of $200 \mathrm{dd}$ (Fig. 2B). This higher spore production per infected patch compensates the delay in canopy colonization by leading to a higher number of infected patches within the age classes it has already reached (horizontal foliar spread or sideways colonization of the canopy). From a biological point of view, the infection of patches within age classes in our model corresponds to a horizontal sideways spatial pathogen dispersal in the field, whereas the infection of new age classes corresponds to a vertical upward infection of new leaf layers. In other words, the pathogen strain with $\lambda=40 \mathrm{dd}$ progresses faster upward (to reach the top of the canopy) than sideways (to infect all leaves with the same age), efficiently colonizing young age classes, whereas the strain with $\lambda=200 \mathrm{dd}$ progresses faster sideways than upward, efficiently infecting patches in the already-colonized age classes.

At $T=1,400 \mathrm{dd}$, the pathogen strain with the intermediate latent period $(\lambda=120 \mathrm{dd}$ ) has progressed upward almost as much as the strain with the short latent period (it has reached almost as many age classes of young patches; Fig. 1C, arrow) and has infected more patches than the two other latent periods and strains (Fig. 2A). The success of the intermediate latent period becomes even more pronounced at $T=1,600 \mathrm{dd}$ : The pathogen has reached the top of the canopy just like that with the short latent period (Fig. 1D) and has colonized more patches than any other strain (Fig. 2A). It has produced more spores than the strain with the long latent period at this stage, although the latter remains most productive at the end of the season (Fig. 2B). Hence, the intermediate latent period, which compromises between fast upward canopy colonization and high local spore production, maximizes the number of infected patches over the course of the epidemic. It therefore maximizes the AUDPC.

We calculated the invasion fitness for different values of the three plant traits affected by fertilization. The results are represented in the form of PIPs (Supplementary Fig. S1). All PIPs display an evolutionary attractor of the invasion dynamics, which is the adaptive dynamics equivalent of the optimal latent period with the optimization principle. These singular strategies (points of intersection of the zero-isoclines on the PIPs in Supplementary Fig. $\mathrm{S} 1$ ) correspond to a maximum of fitness, because invasion fitness is negative both above and below the singular strategy. Theoretically, singular points that are both attractive and evolutionarily stable are called continuously stable strategies (Metz et al. 1996). Yet because
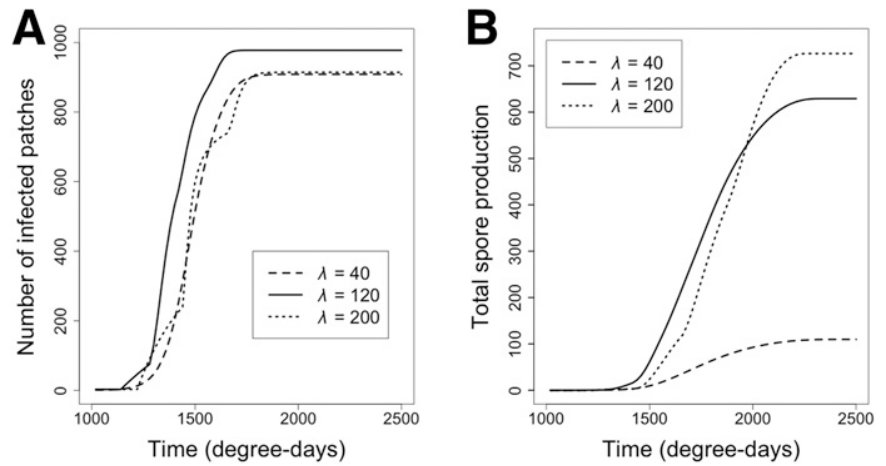

Fig. 2. Effect of latent period $\lambda$ on $\mathbf{A}$, the seasonal dynamics of infected patches (disease progress curves) at equilibrium and $\mathbf{B}$, the seasonal dynamics of spore production at equilibrium. Canopy infection occurs at 1,000 dd. Fertilization parameters: $K=5, \rho=1$, and $\tau=1,000$. Dashed line, short latent period $(\lambda=40 \mathrm{dd})$; solid line, intermediate latent period $(\lambda=120 \mathrm{dd})$; dotted line, long latent period $(\lambda=200 \mathrm{dd})$. 
this terminology is obscure, we will refer to them as ESSs. Note that all the PIPs are apparently symmetric with respect to the first diagonal, which is consistent with the existence of an evolutionary optimization principle (Metz et al. 2008).

The ESSs obtained with invasion fitness are plotted in Figure 3 (asterisks). The ESS latent period responds quite differently to the
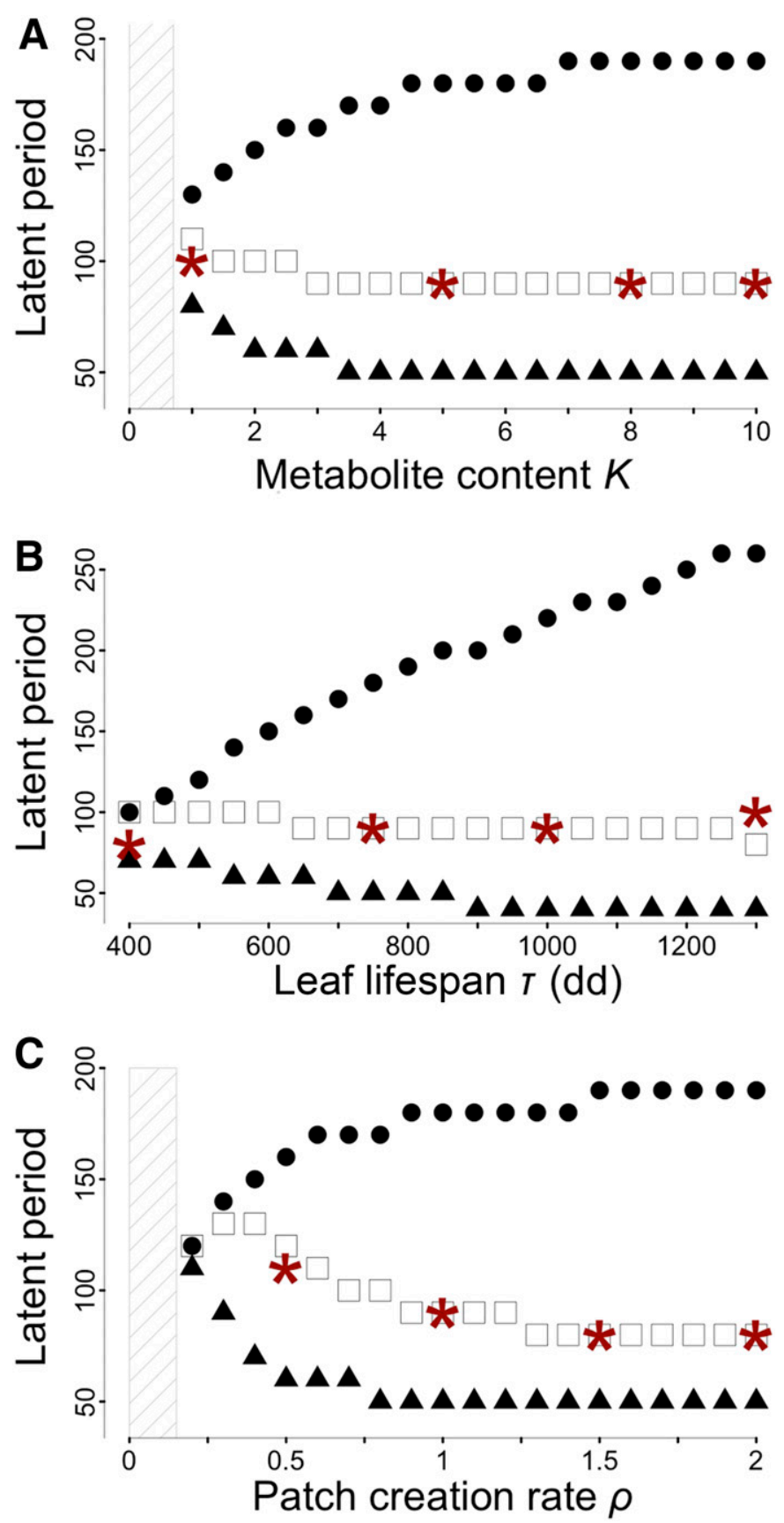

Fig. 3. Variation of optimal latent periods and invasion fitness with values of plant traits (fertilization) for $\mathbf{A}$, the metabolite concentration effect; $\mathbf{B}$, the leaf lifespan effect; and $\mathbf{C}$, the leaf area index effect. Full circles are optimal latent periods corresponding to seasonal spore production as a fitness measure. Full triangles are optimal latent periods corresponding to within-season exponential growth rate as a fitness measure of the pathogen. Open squares are optimal latent periods corresponding to the area under disease progress curve as a fitness measure. Asterisks represent the invasion fitness and correspond to evolutionary singular strategies. There are no sustainable epidemics in the striped areas of the parameter space. The first three values of optimal latent periods on $\mathbf{A}$ (filled circles and triangles corresponding to $K=1,1.5$, and 2, respectively) were already published in Précigout et al. (2017, Fig. 7A). $K$, patch resource carrying capacity; $\rho$, maximum patch creation rate; $\tau$, patch lifespan. three plant traits tested. First, it responds poorly to increased foliar metabolites (MC, Fig. 3A) and LL (Fig. 3B), but the response is more pronounced for canopy size (LAI, Fig. 3C). Second, different responses are observed because the ESS latent period increases slightly with LL but decreases with foliar metabolite content (only slightly, however) and canopy size.

Figure 3 allows the comparison between the ESS latent period (asterisks) and optimal latent periods obtained with the three empirical fitness measures (circles, triangles, and squares). When pathogen fitness is defined as the seasonal spore production $P\left(T_{\text {end }}\right)$, we find a strong positive relation between optimal latent periods and fertilization (Fig. 3, circles). By contrast, when fitness is defined as the within-season exponential growth rate of the pathogen $r$, we find a strong negative relation between optimal latent periods and fertilization (Fig. 3, triangles). These results are consistent for the three plant traits affected by fertilization (Fig. 3A to 3C). Finally, when pathogen fitness is defined as the AUDPC, the optimal latent period decreases with increasing foliar MC (Fig. 3A squares), LL (Fig. 3B squares), and canopy size (LAI, Fig. 3C squares) but with a much less pronounced effect for MC and LL. Of the three pathogen fitness measures used, the ESS latent periods are closest to the optimal latent periods that maximize the AUDPC. The ESS and latent periods maximizing AUDPC are similar with identical trends except for the response to the shortest and the longest tested LL values.

As mentioned in the Materials and Methods section, a PIP does not show the outcome of between-strain competition, because it is assumed that the invader has no impact on density dependence. Yet the invasion fitness concept can be used to infer conclusions about the scope for two strains to coexist. Indeed, a minimal condition for the global coexistence of two populations is that each strain can invade the steady state of the other one. In other words, mutual invasibility is a condition for coexistence. The PIP can hence be used to detect combinations of latent periods that can mutually invade each other's steady state. In adaptive dynamics, a useful tool to this end is the so-called trait evolution plot (Metz et al. 1996). This plot simultaneously synthesizes the signs of the two fitness functions $f\left(\lambda_{2}, \lambda_{1}\right)$ and $f\left(\lambda_{1}, \lambda_{2}\right)$. Only combinations of latent periods for which both functions have a positive sign correspond to pairs of mutually invading strains. In Figure 4, the mutual invasibility of pairs $f\left(\lambda_{1}, \lambda_{2}\right)$ is colored in medium gray. Indeed, the figure shows that mutual invasibility is extremely rare in our model. Coexistence is impossible at low fertilization (data not shown) and marginally possible at medium and high fertilization for the three tested plant traits (Fig. 4). Moreover, provided mutations have small phenotypic effects (i.e., evolution is restricted along the diagonal), the "invasion implies fixation" principle holds true, so that any invading mutant will replace the resident and coexistence is impossible (Geritz 2005; Geritz et al. 2002).

\section{DISCUSSION}

Using an epidemiological model of wheat rust epidemics (Précigout et al. 2017), we studied the evolutionary response of such biotrophic pathogens to changes in three plant traits driven by crop fertilization. MC, LL, and crop growth rate are the three main effects of fertilization on the crop (Lovell et al. 1997; Marschner 1986; Robert et al. 2002, 2004, 2006; Spiertz and De Vos 1983). Four fitness measures were defined to study several possible evolutionary responses of the pathogen latent period to changes in fertilization levels. Three of these fitness measures are called empirical fitness measures because they correspond to response variables that are potentially measurable in experiments. These measures are (i) the seasonal spore production, (ii) the withinseason exponential growth rate of the pathogen population, and (iii) the AUDPC. The fourth corresponds to the more theoretical invasion fitness from adaptive dynamics (Metz et al. 1992). In this article we compared the predictions for the outcome of the evolution 
of the latent period based on the optimization principle, often used in classic evolutionary ecology (Roff 2002; Stearns 1992), applied to these three ad hoc fitness measures (Précigout et al. 2017) with the rigorous approach of adaptive dynamics.

We examined how the different effects of fertilization on the crop influence evolution of the latent period, focusing on the effect of fertilization on the optimal and ESS latent periods. Our results show that empirical fitness measures for the seasonal spore production and growth rate of the pathogen population do not give the same response as the adaptive dynamics approach based on invasion fitness. The ESS latent period is generally in between the latent periods that maximize either of these two empirical fitness measures. The results of the AUDPC empirical fitness measure are similar to those of the ESS latent periods. In other words, we can conclude that the ESS latent period maximizes neither the seasonal spore production nor the estimated within-season exponential growth rate but instead seems to maximize the AUDPC of the epidemics.

According to Lion and Metz (2018), the fact that the maximized quantity in our model is not the $R_{0}$ (approximated here by the
A

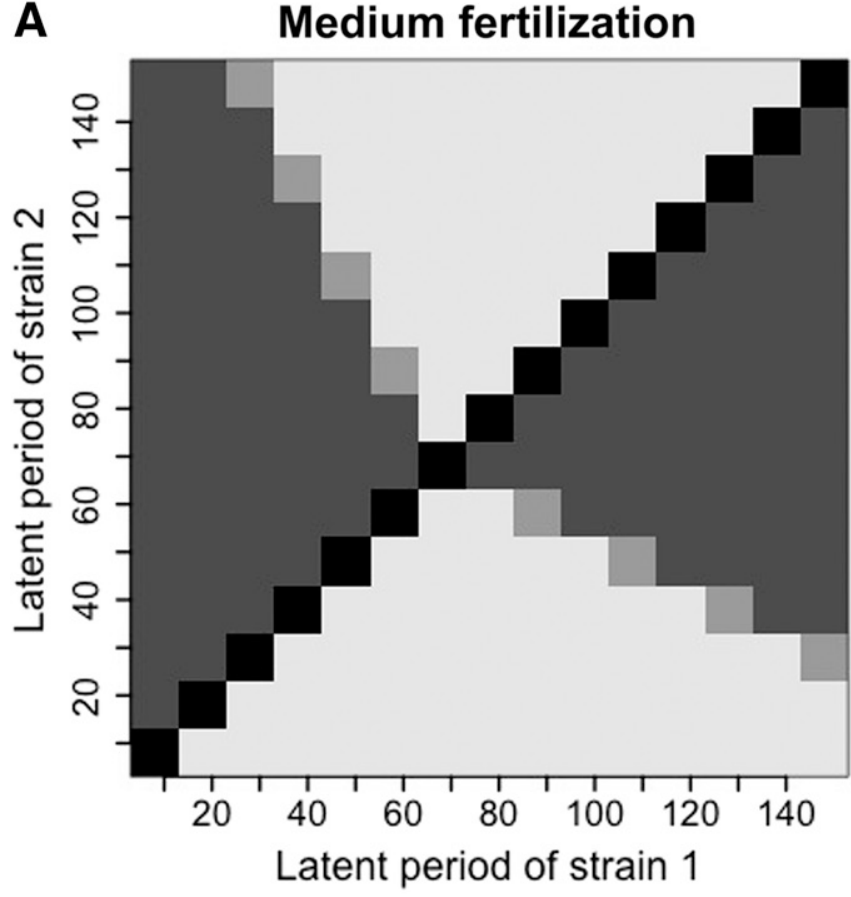

C Long leaf lifespan $(r=1300 \mathrm{dd})$

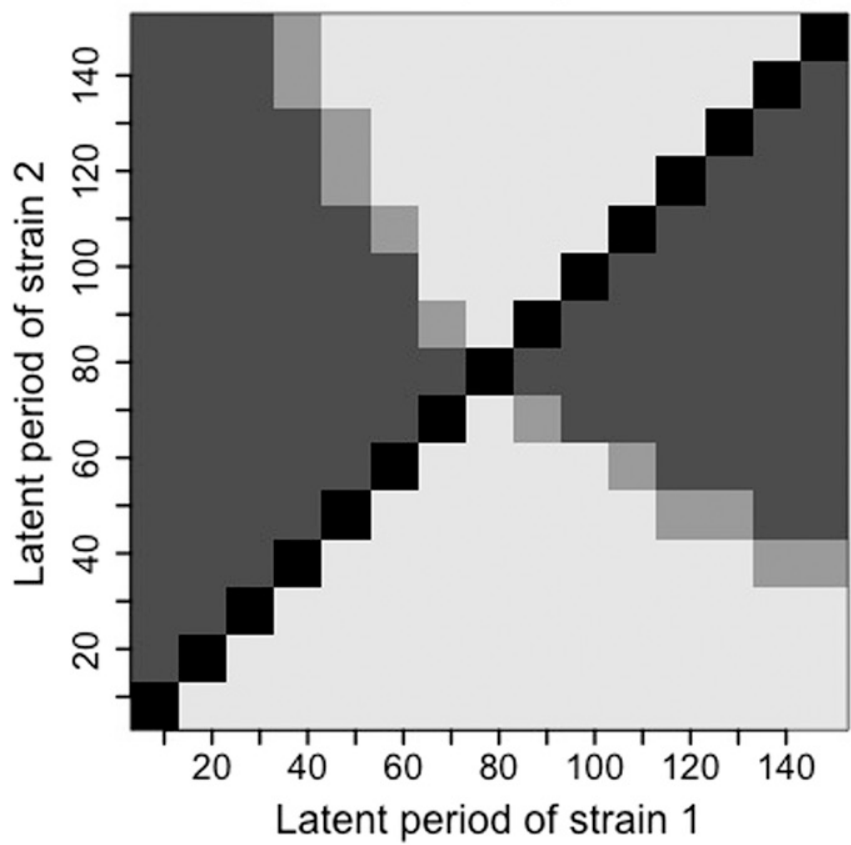

B

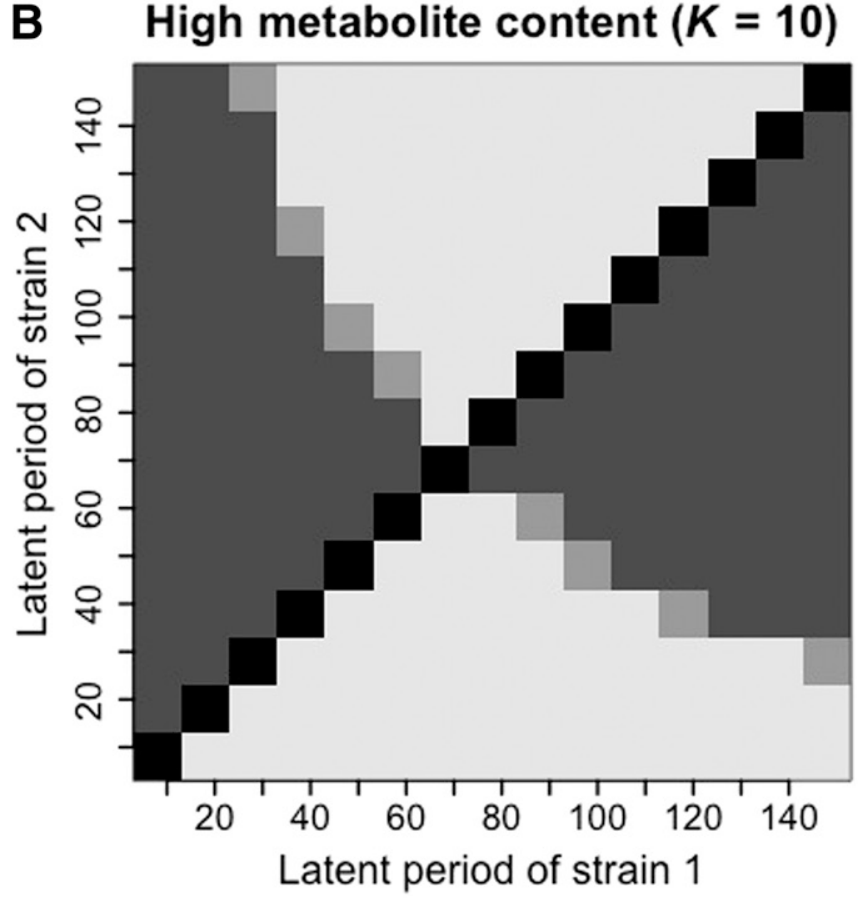

D High rate of patch creation $(\rho=2)$

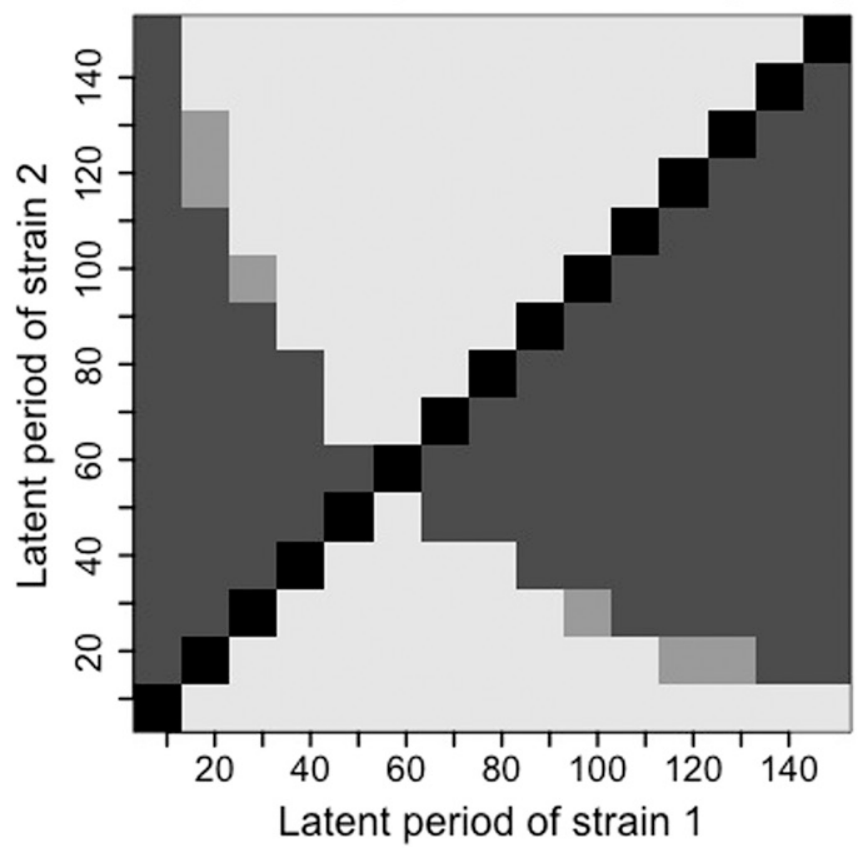

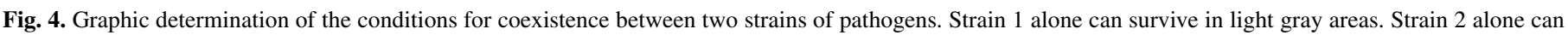

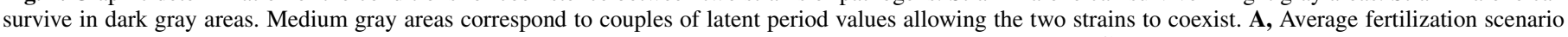

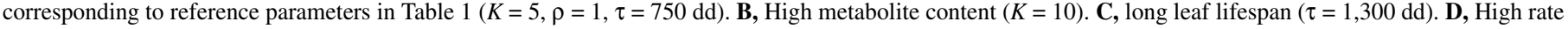
of patch creation $(\rho=2)$. $K$, patch resource carrying capacity; $\rho$, maximum patch creation rate; and $\tau$, patch lifespan. 
estimated within-season exponential growth rate of the pathogen) is not a surprise. Indeed, in our model the population of patches infected by the pathogen has a double age structure: in terms of the age of the patches (the amount of resource in the patches decreases over time) and the age of infection (the pathogen diverts the resource to its advantage). In terms of between-strain competition, the interaction environment of a mutant strain therefore corresponds to the potentially very high number of variables needed to describe the age structure of the resident population. In Lion and Metz (2018), such complex form of environmental feedback precludes $R_{0}$ maximization.

Theoretically, we know that the optimization principle gives the same results as an invasion analysis only when the densitydependent interactions between competing strains can be characterized by a single (constant) number such as a single resource concentration (Metz et al. 2008; Mylius and Diekmann 1995). In our model, the interaction environment is more complex, being the temporally fluctuating physiological distribution of susceptible patches. However, the fact that we assume that the pathogen dynamics are driven by a bottleneck passage in between years, during which the population is characterized by a single number (the amount of spores initiating the next year's epidemic), does give some scope for a simple fitness proxy being maximized at the ESS. This finding is consistent with the result that maximizing the AUDPC, a simple number, gives results close to the ESS based on the multidimensional interaction environment. Hamelin et al. (2011) developed a polycyclic fungal disease model that is biologically similar to ours. The two major differences with our work are the presence of a trade-off between intra-annual and interannual transmission and the fact that they do not use a physiological structure of the population but a slow-fast dynamic system. They demonstrate that in their model, invasion fitness is two-dimensional in the environment and even one-dimensional in the absence of secondary infections. In the latter case, invasion fitness depends only on the average density of healthy hosts. Considering that AUDPC is mathematically linked to the integral of susceptible host tissue over the season, our finding that AUDPC maximization is fairly close to the invasion fitness is in agreement with Hamelin et al. (2011).

AUDPC: intermediate fitness measure as the winning strategy. We found that the latent periods maximizing the AUDPC often correspond or are close to the ESS of the invasion analysis. The winning strategy in our model therefore infects the highest number of patches. We show that the optimal latent period has an intermediate value between a short and a long latent period. A short latent period certainly favors the infection of new leaves emerging at the top of the canopy (vertical dispersion) but produces few spores and therefore infects few tissues. A long latent period certainly produces many spores locally and thus strongly infects already infected leaf stages (horizontal dispersion) but slowly rises upward in the canopy. The ESS latent period corresponds to a latent period that finds a compromise between efficient horizontal and vertical dispersal within the crop canopy. An intermediate latent period results in the colonization of more patches than any other latent period while reaching the top of the canopy almost as quickly as strains with short latent periods. These results are consistent with the findings of Précigout et al. (2017), who identified two trade-offs, both mediated by the latent period, that determine the pace and intensity of the epidemiological dynamics: patch-foliar level mycelium growth versus spore production (as in Pariaud et al. 2013) and the speed of colonizing the vertical canopy structure (as in Robert et al. 2018).

In our model, we assume that the environment of interacting pathogen strains is the distribution of susceptible patches, that is, the healthy part of the canopy. Strains are hence in competition for the healthy part of the canopy. Based on simple ecological concepts such as competitive exclusion and $R^{*}$ competition (Tilman 1982), it thus makes sense that a strategy minimizing the healthy part of the canopy over a growing season is a winning strategy. Based on this conjecture, we included the AUDPC as a third empirical fitness measure in our study in the first place. Indeed, a strain that maximizes the AUDPC (a cumulative measure of the number of infected patches over time) automatically minimizes the amount of remaining healthy tissue. In our model, such a strategy corresponds to intermediate latent periods, which find a compromise between the abovementioned epidemiological processes.

Finally, we find an interesting parallel between our model and models coupling within-host and between-host evolution. The study of the evolutionary consequences of conflicts between withinand between-host dynamics (such as the virulence/dispersion tradeoff; Alizon and van Baalen 2008; Gilchrist and Sasaki 2002) usually deals with nested models that allow one to explicitly link parameters of the between-host model to the behavior of the within-host model. In such models, the ESS is often found to strike a balance between the two levels of selection (within-host on the one hand, betweenhost on the other hand). In the present study, the scale of the plant is not modeled explicitly; the canopy consists of a distribution of patches corresponding to elementary leaf surfaces. In our model, the ESS latent period has an intermediate value between a short latent period, which rapidly colonizes a large number of patches, and a long latent period, which converts a maximum of patch resources into mycelium or spores biomass.

Conjecturing about pathogen latent period evolution in the field. Both the ESS and AUDPC optimal latent periods present contrasting results depending on which effect of fertilization on plants is considered. Regarding the leaf MC effect, we expect the latent period to increase with a reduction in fertilization. However, the increase is limited, and for the MC effect, we could expect almost no evolutionary change in the latent period accompanying a change in the fertilization level. Regarding the LL effect, we expect the latent period to decrease with a reduction in fertilization. Decreasing fertilization will induce LL reduction, leading to canopies with more rapid leaf senescence, which should intensify the local foliar race between the plant and the pathogen for leaf colonization (Robert et al. 2018). It is then understandable that the pathogen will adapt to such a faster foliar senescence by speeding up its infection cycle, hence decreasing its latent period. Finally, for the LAI effect, the evolutionary response to a decrease in fertilization is an increase in the latent period. Decreasing the growth rate of the crop canopy would potentially have the opposite effect to decreasing the LL: It can slow down the race between the plant and the pathogen. This release could allow the pathogen to take more time to increase its local spore production while keeping up with canopy development for tissue colonization. Decreasing the rate of canopy colonization would then allow longer pathogen latent periods.

In the field, crops respond to changes in fertilization by changing their LAI, LL, and MC together (Barillot et al. 2016; Bertheloot et al. 2007; Ferrise et al. 2010; Robert et al. 2004; Savary et al. 1995). Our results suggest the potential opposite evolutionary responses of the latent period to these effects of fertilization on plants. A likely outcome could be no detectable change in the latent period. However, because wheat responds to fertilization first by changing its canopy size (especially through reduced tillering), our results suggest that reducing fertilization could favor pathogen strains with longer latent periods. However, because of our contrasting results, a straightforward conclusion does not seem possible, and an interesting perspective would be to mimic a more realistic scenario of fertilization with our model, accounting for the simultaneous effects on the different plant traits. The experimental evolution on pathosystems (Fisher and Lang 2016; Lehman and Shaner 1997; Zhan and McDonald 2013b) with varying levels of fertilization also would be highly valuable to better interpret our results.

This work allowed us to study the evolutionary responses of pathogens to soft regulation practices (in this case through changes in three plant traits). We are aware of only a few studies on the 
evolutionary responses of pests to soft regulation practices to date. Most of the work on pest adaptation has instead focused on hard regulation practices such as the use of pesticides and resistant crop varieties. Here, we show that pathogens will probably respond evolutionarily to soft regulation practices that challenge their sustainability (Zhan et al. 2015). There is clearly a need for more information on the adaptation of pathogens to soft regulation practices and their sustainability. For example, many studies demonstrate a strong relation between plant architecture and pathogen development (Baccar et al. 2011; Calonnec et al. 2008; Garin et al. 2014; Robert et al. 2008, 2018) but without including possible evolutionary outcomes of pathogen adaptation to changes in plant architecture. Our study shows the diverse potential responses of the pathogen latent period to changes in several plant traits.

Evolutionary ecology: optimization or invasion analysis? We have compared two different conceptual approaches, both of which are frequently used in evolutionary ecology: the optimization principle, based on ad hoc fitness definitions, which is popular in life history theory (Roff 2002) and behavioral ecology (Stearns 1992), and an invasion analysis based on adaptive dynamics (Metz et al. 1996). It is tempting to ask the question: Which one is better? And which fitness definition should we use? Although it is true that fitness is rigorously defined in adaptive dynamics, we argue that this does not necessarily mean that its definition is more relevant than the so-called ad hoc fitness measures used in the optimization approach. The Achilles heel of fitness definitions in adaptive dynamics is that it all depends on how one chooses to model the density-dependent interactions between competing strains. Had we chosen to model within-canopy competition differently, for instance, by allowing for the coinfection of patches, we could have obtained different results. Alternative assumptions such as spatial dynamics, dispersal during the growing season, additional host populations, and a direct effect of lesions on photosynthesis are likely to influence the outcome. A second problem with invasion fitness is the difficulty of measuring it in the field. We argue that comparisons of these two approaches, invasion and old-fashioned empirical fitness measures, are an interesting way forward in this context. Identifying empirical fitness measures that seem consistent with invasion analysis allows us to understand the fitness measure itself (in terms of the underlying dynamics) and can provide testable predictions for field experiments.

Conclusion. In this article, we use a model to study the evolutionary response of foliar biotrophic fungal pathogens to changes in their host's fertilization level. For this purpose, we compared the predictions for the outcome of the evolution of the latent period based on the optimization principle, often used in classic evolutionary ecology, using three ad hoc empirical fitness measures with the rigorous approach of adaptive dynamics. Interestingly, we found that the three empirical fitness measures give contrasting results but that the ESS latent period is close to the latent period that maximizes the AUDPC, which corresponds to the intensity of the epidemic. This result supports those of Spielman et al. (1992), who found that the AUDPC represents the best fitness characteristic of different strains of Phytophthora infestans. We found that the ESS latent period varies with changes in LL and canopy growth rate, thus leading to the potential evolution of pathogens to soft pathogen regulation practices.

\section{ACKNOWLEDGMENTS}

We dedicate this article to our dear colleague David Claessen, who passed away last year. This article is full of his ideas, thoughts, and modeling style. We had the great privilege of working with him and benefiting from his scientific guidance and remarkable personality.

\section{LITERATURE CITED}

Agrios, G. N. 2005. Plant diseases caused by fungi. Pages 274-276 in: Plant Pathology, 5th ed. Academic Press, Cambridge, MA.
Alizon, S., and Van Baalen, M. 2008. Multiple infections, immune dynamics, and the evolution of virulence. Am. Nat. 172:E150-E168.

Baccar, R., Fournier, C., Dornbusch, T., Andrieu, B., Gouache, D., and Robert, C. 2011. Modelling the effect of wheat canopy architecture as affected by sowing density on Septoria tritici epidemics using a coupled epidemicvirtual plant model. Ann. Bot. (Lond.) 108:1179-1194.

Balodi, R., Ghatak, L. V., Bisht, S., and Shukla, N. 2017. Reproductive fitness of fungal phytopathogens: Deriving co-evolution of host-pathogen systems. Pages 41-64 in: The Phytopathogen: Evolution and Adaptation. Apple Academic Press, Palm Bay, FL.

Barillot, R., Chambon, C., and Andrieu, B. 2016. CN-Wheat, a functionalstructural model of carbon and nitrogen metabolism in wheat culms after anthesis. II. Model evaluation. Ann. Bot. (Lond.) 118:1015-1031.

Bertheloot, J., Andrieu, B., Fournier, C., Martre, P., and The Horticulture and Food Research Institute of New Zealand. 2007. A model of nitrogen distribution and senescence in virtual wheat. Page 18 in: Functional-Structural Plant Models. Abstracts of papers and posters. Presented at 5th International Workshop, Napier, NZ.

Biffen, R. H. 1905. Mendel's laws of inheritance and wheat breeding. J. Agric. Sci. 1:4-48.

Bockus, W. W., and Shroyer, J. P. 1998. The impact of reduced tillage on soilborne plant pathogens. Annu. Rev. Phytopathol. 36:485-500.

Bousset, L., and Chèvre, A. M. 2013. Stable epidemic control in crops based on evolutionary principles: Adjusting the metapopulation concept to agroecosystems. Agric. Ecosyst. Environ. 165:118-129.

Brent, K. J., and Hollomon, D. W. 2007. Fungicide Resistance in Crop Pathogens: How Can It Be Managed? FRAC Monogr. no. 1. 2nd rev. ed. Fungicide Resistance Action Committee 2007, CropLife International, Brussels, Belgium.

Calonnec, A., Cartolaro, P., Naulin, J. M., Bailey, D., and Langlais, M. 2008. A host-pathogen simulation model: Powdery mildew of grapevine. Plant Pathol. 57:493-508.

Claessen, D., and Dieckmann, U. 2002. Ontogenetic niche shifts and evolutionary branching in size-structured populations. Evol. Ecol. Res. 4: 189-217.

de Roos, A.M. 1997. A gentle introduction to physiologically structured population models. Pages 119-204 in: Structured-Population Models in Marine, Terrestrial, and Freshwater Systems.

de Roos, A. M. 2014. EBTtool: Escalator Boxcar Train tool. Institute for Biodiversity and Ecosystem Dynamics, Amsterdam, The Netherlands. https://staff.fnwi.uva.nl/a.m.deroos/EBT/

Deising, H. B., Reimann, S., and Pascholati, S. F. 2008. Mechanisms and significance of fungicide resistance. Braz. J. Microbiol. 39:286-295.

Denison, R. F. 2012. Darwinian Agriculture: How Understanding Evolution Can Improve Agriculture. Princeton University Press,Princeton, NJ.

Diekmann, O. 2004. A beginner 's guide to adaptive dynamics. Banach Cent. Publ. 63:47-86.

Dordas, C. 2008. Role of nutrients in controlling plant diseases in sustainable agriculture: A review. Agron. Sustain. Dev. 28:33-46.

Duvivier, M., Dedeurwaerder, G., Bataille, C., De Proft, M., and Legrève, A. 2016. Real-time PCR quantification and spatio-temporal distribution of airborne inoculum of Puccinia triticina in Belgium. Eur. J. Plant Pathol. 145:405-420.

El Jarroudi, M., Kouadio, L., Delfosse, P., and Tychon, B. 2014. Brown rust disease control in winter wheat: I. Exploring an approach for disease progression based on night weather conditions. Environ. Sci. Pollut. Res. 21: 4797-4808.

Fabre, F., Rousseau, E., Mailleret, L., and Moury, B. 2015. Epidemiological and evolutionary management of plant resistance: Optimizing the deployment of cultivar mixtures in time and space in agricultural landscapes. Evol. Appl. 8:919-932.

Ferrise, R., Triossi, A., Stratonovitch, P., Bindi, M., and Martre, P. 2010. Sowing date and nitrogen fertilisation effects on dry matter and nitrogen dynamics for durum wheat: An experimental and simulation study. Field Crops Res. 117:245-257.

Fisher, K. J., and Lang, G. I. 2016. Experimental evolution in fungi: An untapped resource. Fungal Genet. Biol. 94:88-94.

Fisher, M. C., Hawkins, N. J., Sanglard, D., and Gurr, S. J. 2018. Worldwide emergence of resistance to antifungal drugs challenges human health and food security. Science 360:739-742.

French, E., Kim, B. S., and Iyer-Pascuzzi, A. S. 2016. Mechanisms of quantitative disease resistance in plants. Semin. Cell Dev. Biol. 56:201-208.

Garin, G., Fournier, C., Andrieu, B., Houlès, V., Robert, C., and Pradal, C. 2014. A modelling framework to simulate foliar fungal epidemics using functional-structural plant models. Ann. Bot. (Lond.) 114:795-812.

Geritz, S. A. H. 2005. Resident-invader dynamics and the coexistence of similar strategies. J. Math. Biol. 50:67-82.

Geritz, S. A. H., Gyllenberg, M., Jacobs, F. J. A., and Parvinen, K. 2002. Invasion dynamics and attractor inheritance. J. Math. Biol. 44:548-560. 
Geritz, S. A. H., Kisdi, É., Meszéna, G., and Metz, J. A. J. 1998. Evolutionarily singular strategies and the adaptive growth and branching of the evolutionary tree. Evol. Ecol. 12:35-57.

Gilchrist, M. A., and Sasaki, A. 2002. Modeling host-parasite coevolution: A nested approach based on mechanistic models. J. Theor. Biol. 218:289-308.

Gilchrist, M., Sulsky, D. L., and Pringle, A. 2006. Identifying fitness and optimal life-history strategies for an asexual filamentous fungus. Evolution 60:970-979.

Gilligan, C. A. 2007. Sustainable agriculture and plant diseases: An epidemiological perspective.Phil. Trans. R. Soc. B Biol. Sci. 363:741-759.

Gullino, M. L., Leroux, P., and Smith, C. M. 2000. Uses and challenges of novel compounds for plant disease control. Crop Prot. 19:1-11.

Hahn, M. 2014. The rising threat of fungicide resistance in plant pathogenic fungi: Botrytis as a case study. J. Chem. Biol. 7:133-141.

Hamelin, F. M., Castel, M., Poggi, S., Andrivon, D., and Mailleret, L. 2011. Seasonality and the evolutionary divergence of plant parasites. Ecology 92: 2159-2166.

Hartl, D. L., and Clark, A. G. 1997. Principles of Population Genetics. Sinauer Associates, Sunderland, MA.

Hayes, L. E., Sackett, K. E., Anderson, N. P., and Flowers, M. D. 2016. Evidence of selection for fungicide resistance in Zymoseptoria tritici populations on wheat in western Oregon. Plant Dis. 100:483-489.

Hewitt, H. G. 1998. Fungicides in Crop Protection. CAB International, Wallingford, UK.

Kilpatrick, R. A. 1975. New wheat cultivars and longevity of rust resistance, 1971-75. NE-64:1-20. US Department of Agriculture. Agricultural Research Service, Washington, DC

Lehman, J. S., and Shaner, G. 1997. Selection of populations of Puccinia recondita $\mathrm{f}$. sp. tritici for shortened latent period on a partially resistant wheat cultivar. Phytopathology 87:170-176.

Lion, S., and Metz, J. A. J. 2018. Beyond R0 maximisation: On pathogen evolution and environmental dimensions. Trends Ecol. Evol. 33:458-473.

Lovell, D. J., Parker, S. R., Hunter, T., Royle, D. J., and Coker, R. R. 1997. Influence of crop growth and structure on the risk of epidemics by Mycosphaerella graminicola (Septoria tritici) in winter wheat. Plant Pathol. 46:126-138.

Ma, Z. H., and Michailides, T. J. 2005. Advances in understanding molecular mechanisms of fungicide resistance and molecular detection of resistant genotypes in phytopathogenic fungi. Crop Prot. 24:853-863.

Madden, L. V., Hughes, G., and van den Bosch, F. 2007. The Study of Plant Disease Epidemics. The American Phytopathological Society, St. Paul, MN.

Marschner, H. 1986. Mineral Nutrition of Higher Plants. Academic Press, London.

McDonald, B. A., and Linde, C. 2002. Pathogen population genetics, evolutionary potential, and durable resistance. Annu. Rev. Phytopathol. 40:349-379.

McIntosh, R., and Brown, G. N. 1997. Anticipatory breeding for resistance to rust diseases in wheat. Annu. Rev. Phytopathol. 35:311-326.

Metz, J. A. J., Geritz, S. A. H., Meszena, G., Jacobs, F. J. A., and van Heerwaarden, J. S. 1996. Adaptive dynamics, a geometrical study of the consequences of nearly faithful reproduction. Pages 183-231 in: Stochastic and Spatial Structures of Dynamical Systems. S. J. van Strien and S. M. Verdyan Lunel, eds. North Holland, Amsterdam, The Netherlands.

Metz, J. A. J., Mylius, S. D., and Diekmann, O. 2008. When does evolution optimize? Evol. Ecol. Res. 10:629-654.

Metz, J. J., Nisbet, R. M., and Geritz, S. H. 1992. How should we define "fitness" for general ecological scenarios? Trends Ecol. Evol. 7:198-202.

Mikaberidze, A., Mcdonald, B. A., and Bonhoeffer, S. 2015. Developing smarter host mixtures to control plant disease. Plant Pathol. 64:996-1004.

Mundt, C. C. 2002. Une of multiline cultivars and cultivar mixtures for disease management. Annu. Rev. Phytopathol. 40:381-410.

Mundt, C. C. 2014. Durable resistance: A key to sustainable management of pathogens and pests. Infect. Genet. Evol. 27:446-455.

Mylius, S. D., and Diekmann, O. 1995. On evolutionarily stable life histories, optimization and the need to be specific about density dependence. Oikos 74:218-224.

Oz, T., Guvenek, A., Yildiz, S., Karaboga, E., Tamer, Y. T., Mumcuyan, N., Ozan, V. B., Senturk, G. H., Cokol, M., Yeh, P., and Toprak, E. 2014. Strength of selection pressure is an important parameter contributing to the complexity of antibiotic resistance evolution. Mol. Biol. Evol. 31:2387-2401.

Pariaud, B., Ravigné, V., Halkett, F., Goyeau, H., Carlier, J., and Lannou, C. 2009. Aggressiveness and its role in the adaptation of plant pathogens. Plant Pathol. 58:409-424.

Pariaud, B., Van den Berg, F., Van den Bosch, F., Powers, S. J., Kaltz, O., and Lannou, C. 2013. Shared influence of pathogen and host genetics on a trade-off between latent period and spore production capacity in the wheat pathogen, Puccinia triticina. Evol. Appl. 6:303-312.

Précigout, P.-A., Claessen, D., and Robert, C. 2017. Crop fertilization impacts epidemics and optimal latent period of biotrophic fungal pathogens. Phytopathology 107:1256-1267.
Pringle, A., and Taylor, J. W. 2002. The fitness of filamentous fungi. Trends Microbiol. 10:474-481.

REX Consortium. 2015. Heterogeneity of selection and the evolution of resistance. Trends Ecol. Evol. 28:110-118.

Rimbaud, L., Papïx, J., Rey, J.-F., Barrett, L. G., and Thrall, P. H. 2018. Assessing the durability and efficiency of landscape-based strategies to deploy plant resistance to pathogens. PLOS Comput. Biol. 14:e1006067.

Robert, C., Bancal, M.-O., and Lannou, C. 2002. Wheat leaf rust uredospore production and carbon and nitrogen export in relation to lesion size and density. Phytopathology 92:762-768.

Robert, C., Bancal, M.-O., and Lannou, C. 2004. Wheat leaf rust uredospore production on adult plants: Influence of leaf nitrogen content and Septoria tritici blotch. Phytopathology 94:712-721.

Robert, C., Bancal, M. O., Lannou, C., and Ney, B. 2006. Quantification of the effects of Septoria tritici blotch on wheat leaf gas exchange with respect to lesion age, leaf number, and leaf nitrogen status. J. Exp. Bot. 57:225-234.

Robert, C., Fournier, C., Andrieu, B., and Ney, B. 2008. Coupling a 3D virtual wheat (Triticum aestivum) plant model with a Septoria tritici epidemic model (Septo3D): A new approach to investigate plant-pathogen interactions linked to canopy architecture. Funct. Plant Biol. 35:997-1013.

Robert, C., Garin, G., Abichou, M., Houlès, V., Pradal, C., and Fournier, C. 2018. Plant architecture and foliar senescence impact the race between wheat growth and Zymoseptoria tritici epidemics. Ann. Bot. (Lond.) 121:975-989.

Roff, D. 2002. Life History Evolution. Sinauer, Sunderland, MA.

Rothrock, C. S. 1992. Tillage systems and plant disease. Soil Sci. 154: 308-315.

Savary, S., Castilla, N., and Elazegui, F. 1995. Direct and indirect effects of nitrogen supply and disease source structure on rice sheath blight spread. Phytopathology 85:959-965.

Sierotzki, H., and Scalliet, G. 2013. A review of current knowledge of resistance aspects for the next-generation succinate dehydrogenase inhibitor fungicides. Phytopathology 103:880-887.

Spielman, L. J., McMaster, B. J., and Fry, W. E. 1992. Relationships among measurements of fitness and disease severity in Phytophthora infestans. Plant Pathol. 41:317-324.

Spiertz, J. H. J., and De Vos, N. M. 1983. Agronomical and physiological aspects of the role of nitrogen in yield formation of cereals. Plant Soil 75: 379-391

Stearns, S. 1992. The Evolution of Life Histories. Oxford University Press, Oxford, UK.

Stockwell, C. A., Hendry, A. P., and Kinnison, M. T. 2003. Contemporary evolution meets conservation biology. Trends Ecol. Evol. 18:94-101.

Thrall, P. H., Barrett, L. G., Dodds, P. N., and Burdon, J. J. 2016. Epidemiological and evolutionary outcomes in gene-for-gene and matching allele models. Front. Plant Sci. 6:1084.

Tilman, D. 1982. Resource competition and community structure. Monogr. Popul. Biol. 17:1-296.

Tooker, J. F., and Frank, S. D. 2012. Genotypically diverse cultivar mixtures for insect pest management and increased crop yields. J. Appl. Ecol. 49:974-985.

Ueda, M., Takeuchi, N., and Kaneko, K. 2017. Stronger selection can slow down evolution driven by recombination on a smooth fitness landscape. PLoS One 12:9e018312074.

Urech, P. A., Staub, T., and Voss, G. 1997. Review: Resistance as a concomitant of modern crop protection. Pestic. Sci. 51:227-234.

van den Berg, F., Bacaer, N., Metz, J. A. J., Lannou, C., and van den Bosch, F. 2011. Periodic host absence can select for higher or lower parasite transmission rates. Evol. Ecol. 25:121-137.

van den Berg, F., Gilligan, C., Bailey, D. J., and van den Bosch, F. 2010. Periodicity in host availability does not account for evolutionary branching as observed in many plant pathogens: An application to Gaeumannomyces graminis var. tritici. Phytopathology 100:1169-1175.

Walker, A., Ravigné, V., Rieux, A., Ali, S., Carpentier, F., and Fournier, E. 2017. Fungal adaptation to contemporary fungicide applications: the case of Botrytis cinerea populations from Champagne vineyards (France). Mol. Ecol. 26:1919-1935

Walters, D. R., and Bingham, I. J. 2007. Influence of nutrition on disease development caused by fungal pathogens: Implications for plant disease control. Ann. Appl. Biol. 151:307-324.

Zhan, J., and McDonald, B. A. 2013a. Experimental measures of pathogen competition and relative fitness. Annu. Rev. Phytopathol. 51:131-153.

Zhan, J., and McDonald, B. A. 2013b. Field-based experimental evolution of three cereal pathogens using a mark-release-recapture strategy. Plant Pathol. 62:106-114.

Zhan, J., Thrall, P. H., and Burdon, J. J. 2014. Achieving sustainable plant disease management through evolutionary principles. Trends Plant Sci. 19: $570-575$.

Zhan, J., Thrall, P. H., Papaix, J., Xie, L., and Burdon, J. J. 2015. Playing on a pathogen's weakness: Using evolution to guide sustainable plant disease control strategies. Annu. Rev. Phytopathol. 53:19-43. 